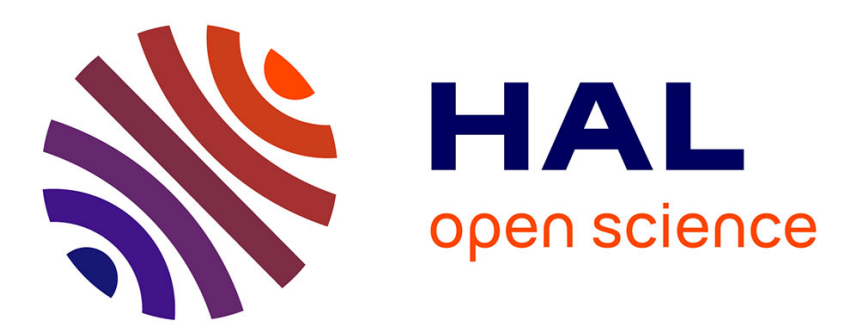

\title{
Measuring hydroperoxide chain-branching agents during n-pentane low-temperature oxidation
}

Anne R Rodriguez, Olivier Herbinet, Zhandong R Wang, Fei R Qi, Christa R Fittschen, Phillip R Westmoreland, Frédérique Battin-Leclerc

\section{- To cite this version:}

Anne R Rodriguez, Olivier Herbinet, Zhandong R Wang, Fei R Qi, Christa R Fittschen, et al.. Measuring hydroperoxide chain-branching agents during n-pentane low-temperature oxidation. Proceedings of the Combustion Institute, 2017, 36, pp.333 - 342. 10.1016/j.proci.2016.05.044 . hal-01464175

\section{HAL Id: hal-01464175 \\ https://hal.science/hal-01464175}

Submitted on 10 Feb 2017

HAL is a multi-disciplinary open access archive for the deposit and dissemination of scientific research documents, whether they are published or not. The documents may come from teaching and research institutions in France or abroad, or from public or private research centers.
L'archive ouverte pluridisciplinaire HAL, est destinée au dépôt et à la diffusion de documents scientifiques de niveau recherche, publiés ou non, émanant des établissements d'enseignement et de recherche français ou étrangers, des laboratoires publics ou privés. 


\title{
Measuring hydroperoxide chain-branching agents during n-pentane low-temperature oxidation
}

\author{
Anne Rodriguez ${ }^{1}$, Olivier Herbinet ${ }^{1}$, Zhandong Wang², Fei Qi ${ }^{2}$, Christa Fittschen ${ }^{3}$, \\ Phillip R. Westmoreland4, Frédérique Battin-Leclerc ${ }^{1}$ \\ ${ }^{1}$ Laboratoire Réactions et Génie des Procédés, CNRS, Université de Lorraine, ENSIC, 1, rue \\ Grandville, BP 20451, 54001 Nancy Cedex, France \\ ${ }^{2}$ National Synchrotron Radiation Laboratory, University of Science and Technology of \\ China, Hefei, Anhui 230029, P. R. China \\ ${ }^{3}$ PhysicoChimie des Processus de Combustion et de l'Atmosphère, CNRS, Université de Lille 1, \\ 59650 Villeneuve d'Ascq, France \\ ${ }^{4}$ Department of Chemical \& Biomolecular Engineering, North Carolina State University, \\ Raleigh, NC 27695-7905, USA
}

\author{
Published in the Proceedings of the Combustion Institute (2017), 36, 333-342 \\ doi:10.1016/j.proci.2016.05.044
}

\begin{abstract}
The reactions of chain-branching agents, such as $\mathrm{H}_{2} \mathrm{O}_{2}$ and hydroperoxides, have a decisive role in the occurrence of autoignition. The formation of these agents has been investigated in an atmospheric-pressure jet-stirred reactor during the low-temperature oxidation of $n$-pentane (initial fuel mole fraction of 0.01 , residence time of $2 \mathrm{~s}$ ) using three different diagnostics: timeof-flight mass spectrometry combined with tunable synchrotron photoionization, time-of-flight mass spectrometry combined with laser photoionization, and cw-cavity ring-down spectroscopy. These three diagnostics enable a combined analysis of $\mathrm{H}_{2} \mathrm{O}_{2}, \mathrm{C}_{1}-\mathrm{C}_{2}$, and $\mathrm{C}_{5}$ alkylhydroperoxides, $\mathrm{C}_{3}-\mathrm{C}_{5}$ alkenylhydroperoxides, and $\mathrm{C}_{5}$ alkylhydroperoxides including a carbonyl function (ketohydroperoxides). Results using both types of mass spectrometry are compared for the stoichiometric mixture. Formation data are presented at equivalence ratios from 0.5 to 2 for these peroxides and of two oxygenated products, ketene and pentanediones, which are not usually analyzed during jet-stirred reactor oxidation. The formation of alkenylhydroperoxides during alkane oxidation is followed for the first time. A recently developed model of $n$-pentane oxidation aids discussion of the kinetics of these products and of proposed pathways for $\mathrm{C}_{3}-\mathrm{C}_{5}$ alkenylhydroperoxides and the pentanediones.
\end{abstract}

Keywords: Jet-stirred reactor; CRDS; Mass spectrometry; $n$-Pentane; Hydroperoxides 


\section{Introduction}

The design of advanced-technology engines requires an accurate understanding of fuel autoignition chemistry [1]. It is well known that autoignition is triggered by the reactions of chain-branching agents such as $\mathrm{H}_{2} \mathrm{O}_{2}$ or hydroperoxides that are responsible for radical number multiplication [2]. Jet-stirred reactors (JSR) have been shown to be very suitable for studying the chemistry occurring prior to autoignition [3]. Tunable synchrotron vacuum-ultraviolet (SVUV) photoionization mass spectrometry (PIMS) combined with molecular-beam sampling has recently been proven to be a successful method to probe hydroperoxides in JSRs [3-4]. However, these species have not yet been analyzed using a mass-spectrometry method not requiring the use of synchrotron radiation.

The first purpose of this paper is then to present new measurements obtained using a laserionization mass spectrometer and to compare them with results obtained using SVUV-PIMS. For the first time, the formation of alkenylhydroperoxides is followed during alkane oxidation. These intermediates have recently been shown to have an important role during the oxidation of alkenes [5], important products of alkane oxidation. The recent SVUV-PIMS analyses during JSR experiments have also enabled detection of oxygenated products that are difficult to quantify by more usual techniques such as gas chromatography [3], notably ketene (rarely quantified in previous JSR studies), and molecules including two carbonyl groups, which we will call diones. The second purpose of this paper is to provide reliable quantification of these products.

The third purpose of this paper is to use cw-cavity ring-down spectroscopy (CRDS), another non-synchrotron-based technique, to follow $\mathrm{H}_{2} \mathrm{O}_{2}$ for a larger fuel. This absolute quantification technique, which requires only the knowledge of the absorption cross-section, has been recently used to probe hydrogen peroxide $\left(\mathrm{H}_{2} \mathrm{O}_{2}\right)$ during $n$-butane [3] and dimethylether [6-7] JSR oxidation.

These three objectives are achieved for the oxidation of $n$-pentane for a large range of equivalence ratios $(0.5-2)$; $n$-pentane is a fuel representative of gasoline components for which several recent investigations, including new model development, have been performed [8-9].

\section{Experimental facilities}

The JSR described below has been associated with three types of analytical tools:

- Molecular-beam sampling into a time-of-flight mass spectrometer combined with SVUV photoionization [10];

- Capillary-tube sampling into a laser single-photon-ionization time-of-flight mass spectrometer;

- Sonic probing into a cw-CRDS optical cell using the near-IR wavelength range [12].

The first type of experiments were performed at the National Synchrotron Radiation Laboratory (NSRL) in Hefei, China, with gases provided by Nanjing Special Gas Factory Co., Ltd. (purity of $+99 \%$ ) and $n$-pentane provided by Aladdin Reagent Co., Ltd. (purity $\geq 99 \%$ ). The second and third types of measurements were performed at LRGP-Nancy with gases provided by Messer (purity of $+99 \%$ ) and $n$-pentane provided by Sigma-Aldrich (purity $\geq 99 \%$ ). Gas and liquid (prior to vaporization) flows were controlled by mass flow controllers. Diluents were He in 
Nancy and Ar in Hefei. The mass-spectrometry and CRDS analyses, including quantification methods, are described in more detail in the Supplementary Material (SM).

\subsection{The jet-stirred reactor}

As described previously [3,5,7,10-12], the reactor consisted of a quartz sphere (volume $\approx 90$ $\mathrm{cm}^{3}$ ) in which diluted reactant mixture entered through four turbulent jets. The heated reactor was operated at constant temperature and pressure. A heated quartz annular preheating zone was used to increase gas temperature to the reactor temperature before entering the sphere; gas-mixture residence time inside the preheater was about a few percent of the residence time inside the reactor. Reaction temperature was measured inside the reactor using type $\mathrm{K}$ thermocouples, finding temperature gradients always lower than $5 \mathrm{~K}$.

\subsection{Molecular-beam sampling and SVUV photoionization mass spectrometry (SVUV-PIMS)}

The JSR was coupled with a Hefei lab-made time-of-flight mass spectrometer through a quartz cone-like nozzle, its tip pierced with a $75-\mu \mathrm{m}$ orifice. A nickel skimmer with a 1.25 -mm-diameter aperture was located $15 \mathrm{~mm}$ downstream from the sampling nozzle. The SVUV photon beam intersected the molecular beam perpendicularly. Resulting ions were analyzed with a time-offlight mass spectrometer with mass resolution $(\mathrm{m} / \Delta \mathrm{m}) \sim 2000$ (see [10-11] for more details). Reactant mole fractions were obtained assuming no reaction below $480 \mathrm{~K}$. For all products apart from carbon oxides and water that were quantified as in [11], mole fractions were calculated at photoionization energy of $11 \mathrm{eV}$ using $n$-pentane signal at $m / z 72$ and its mole fraction as a reference.

\subsection{Capillary-tube sampling with laser single-photon-ionization mass spectrometry (SPI-MS)}

Products were sampled using a heated quartz capillary tube $(200-\mu \mathrm{m}$ diameter, $5-\mathrm{m}$ length, flow of 3-4 $\mathrm{mL} / \mathrm{min}$ ) directly inserted within the jet-stirred reactor. The whole sampling line was heated to $353 \mathrm{~K}$. This temperature was chosen carefully in order to avoid condensation and also to preserve hydroperoxides, which are fragile due to a weak 0-O bond. At the outlet of the heated capillary line, compounds were directly injected in the ionization zone of a reflectron time-of-flight mass spectrometer equipped with dual ion source for electron-impact and singlephoton ionizations (PhotoTOF, Photonion GmbH, Germany, a device custom-developed for LRGP-Nancy). In the measurements described here, VUV photons with a wavelength of $118 \mathrm{~nm}$ $(10.6 \mathrm{eV})$ were used for a single-photon absorption/ionization process. The mass spectrometer covers a mass range of $m / z$ 10-2000 with mass resolution of 2000 and mass sensitivity of 100 ppm. Molefraction calculations were made using propene at $m / z 42$ as a reference (the value measured by gas chromatography at $650 \mathrm{~K}$ ).

\subsection{The sonic probe sampling and cw-CRDS optical cell}


cw-CRDS is a technique which has allowed many successful studies in atmospheric chemistry [13], but it is still not often used in combustion. Coupling of the atmospheric-pressure JSR with a tubular-glass cw-CRDS cell (length: $86 \mathrm{~cm}$, diameter: $0.8 \mathrm{~cm}$ ), maintained at a pressure of 1.33 $\mathrm{kPa}$ through pumping at both ends, was performed by using a tubular quartz probe with a tip orifice of about $150 \mu \mathrm{m}$ diameter [12]. The flow rate in the cell is $0.25 \mathrm{~L} / \mathrm{min}$, while the total flow rate in the reactor is about $1 \mathrm{~L} / \mathrm{min}$. CRDS analyses were carried out in the near infrared at wavenumbers in the 6620-6644 $\mathrm{cm}^{-1}$ range (more details are given in SM). In addition to $\mathrm{H}_{2} \mathrm{O}_{2}$, several other species such as $\mathrm{H}_{2} \mathrm{O}, \mathrm{CH}_{2} \mathrm{O}$, and $\mathrm{C}_{2} \mathrm{H}_{4}$ (see mole fraction profiles in S3) could be quantified using this technique, as isolated absorption lines could be identified. $\mathrm{H}_{2} \mathrm{O}_{2}$ absorption cross sections for several lines have been obtained in separate experiments where the $\mathrm{H}_{2} \mathrm{O}_{2}$ concentration has been derived from $\mathrm{OH}$ decays measured by time-resolved laser-induced fluorescence following $\mathrm{H}_{2} \mathrm{O}_{2}$ photolysis [13].

The uncertainty of mole fractions derived from MS measurements is usually estimated as $\pm 10 \%$ for major species, $\pm 25 \%$ for intermediates with known photoionization cross-sections (PICSs), and at least a factor of 2 for those with estimated PICSs. The uncertainty of mole fractions derived from CRDS measurements is usually estimated to be an average of $\pm 15 \%$.

\section{Experimental and simulation results}

The three apparatuses described above were used to study the oxidation of $n$-pentane between $500 \mathrm{~K}$ and $1100 \mathrm{~K}$, under quasi-atmospheric pressure (1.05 atm), at a mean residence time of $2.00 \pm 0.01 \mathrm{~s}$, and for a fuel initial mole fraction of 0.010 (complete gas-chromatographic analysis of the gases leaving the JSR can be found in [9]). All the experimental data presented here are detailed in an SM spreadsheet. The model used for simulations is that newly proposed by the Galway group [9] with formation reactions of diones adapted from [14]. A few changes have been tested in this mechanism and are listed in SM. Simulations were performed using the OpenSMOKE++ framework [15].

\subsection{Comparison between quantification of some usual combustion products by the two types of mass spectrometry, CRDS, and gas chromatography}

A mass spectrum obtained with the SPI-MS is shown in Figure 1 for the oxidation of $n$-pentane at $600 \mathrm{~K}$. Hydroperoxides, ketene, and diones are observed in addition to formation of several usual combustion products that can also be quantified by gas chromatography or CRDS. The comparable SVUV-PIMS spectrum is included as supplementary material (Figure S3).

To give an idea about the uncertainty of the quantifications, we performed comparisons between mass-spectrometry quantifications obtained for some usual combustion products (fuel and water, carbon oxides, ethylene, and $\mathrm{C}_{1}-\mathrm{C}_{2}$ aldehydes) and results obtained by other techniques (Figures S4 and S5). Note that Figure S4 also shows that the differences in sampling methods and diluents between Nancy and Hefei do not influence the results considering the uncertainty of each diagnostic. For carbon-containing products, it was possible to compare with the gas-chromatographic analyses (GC). For water, formaldehyde, and ethylene, comparison was made with cw-CRDS. An agreement better than 30\% was obtained using the four different analytical techniques (SVUV-PIMS, SPI-MS, cw-CRDS, GC). With SPI-MS, several compounds such $n$-pentane could not be quantified because the signals were overloaded. Also, while some 
$m /$ zpeaks can be seen for larger alkenes or oxygenated compounds in the MS spectra, it is difficult to compare with chromatographic analysis due to the large number of isomers. The Galway model displayed excellent performance in reproducing the JSR data, as already shown by [9] (Figures S4 and S5)

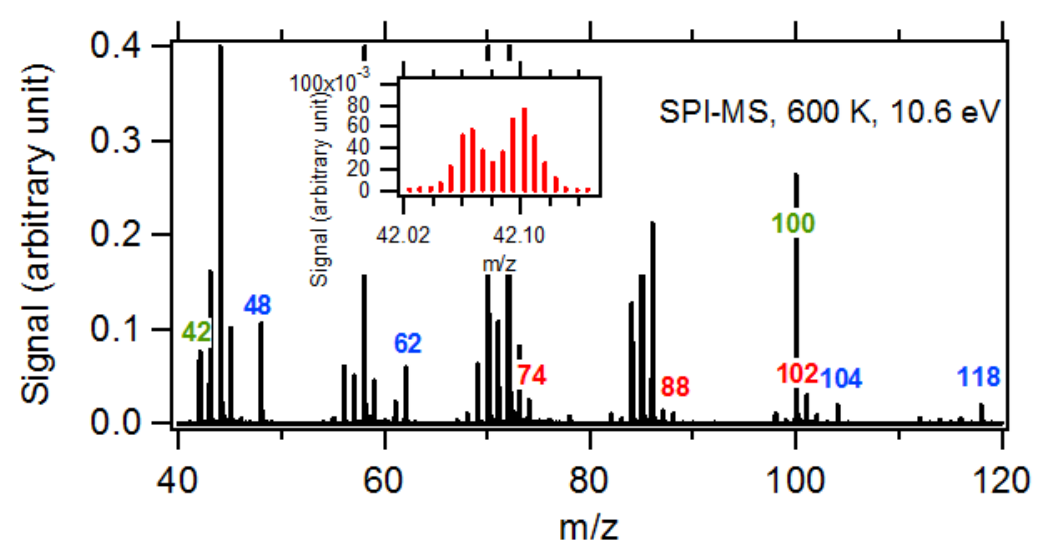

Figure 1: Mass spectrum obtained during stoichiometric $n$-pentane oxidation at $600 \mathrm{~K}$ using SPI-MS (zoomed in the ketene and propene $m / z=42$ region). Numbers are $m / z$ discussed in the text.

\subsection{Ketene quantification}

While ketene is frequently detected in flame experiments [16] and it is also a possible decomposition product of ketohydroperoxides, its detection was only reported recently in a jet-stirred reactor oxidation study of an alkane [9]. Figure 1 shows SPI-MS peaks at $m / z 42$ that correspond to ketene $(\mathrm{m} / \mathrm{z}=42.0367)$ and propene $(\mathrm{m} / \mathrm{z}=42.0797)$. Mass 42 was also observed in SVUV-PIMS. As shown by the enlarged section of Figure 1, with results using the laser photoionization, the two peaks can be resolved, while it was not feasible using SVUV-PIMS [11]. Because the ionization cross-sections of both compounds are well known, their mole fractions can be easily determined. Figure 2 displays the evolution with temperature of the experimental (cross sections from [17]) and simulated mole fractions of ketene for $\varphi$ equal to $0.5,1$, and 2.

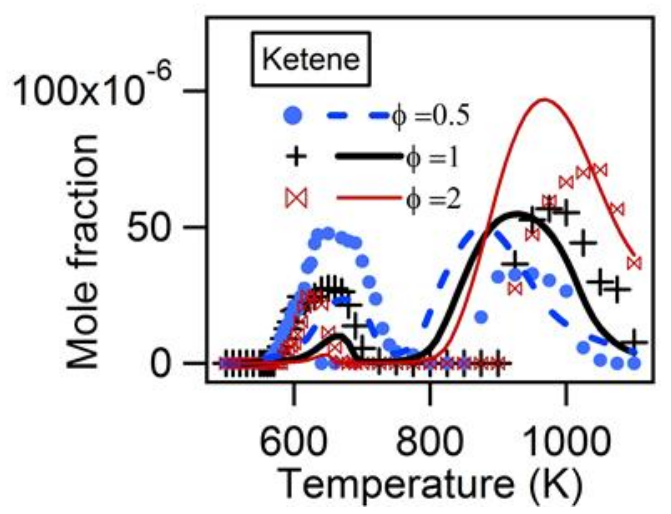

Figure 2: Temperature evolution of ketene mole fraction at different equivalence ratios;

Experimental (SPI-MS, symbols) and computed (with model of [9], lines). 
Between 650 and $800 \mathrm{~K}$, ketene formation increases as $\varphi$ decreases, while the contrary occurs above $900 \mathrm{~K}$. This trend is reproduced well by the model, even if the mole fraction of this compound is underestimated below $800 \mathrm{~K}$ (by a factor of at least 2; the higher $\varphi$, the larger the deviation) and presents a maximum at a simulated temperature lower by $50 \mathrm{~K}$ than in experiments in the high-temperature zone. These deviations indicate that the chemistry of ketene is certainly not yet fully understood.

According to the model [9], at $630 \mathrm{~K}$, ketene is predicted to be formed mainly from the decomposition of $\mathrm{C}_{2} \mathrm{H}_{5} \mathrm{COCH}_{2}$ radicals produced from the decomposition of 1-hydroperoxy-3pentanone. At $880 \mathrm{~K}$, ketene formation is mainly due to secondary reactions of acetone, acetaldehyde, propene, and 1,3-butadiene.

\subsection{Hydroperoxide and dione identification and quantification}

As shown in Figure 1, the SPI-MS mass spectra have peaks at $m / z 48,100,104$, and 118 that correspond to methylhydroperoxide, diones, pentylhydroperoxides, and $\mathrm{C}_{5}$ ketohydroperoxides, respectively. However, because ionizing-photon energy can be tuned in SVUV-PIMS, it is the most suitable tool for species identification. An experimental sweep of photon energies from 8.5 to $11.0 \mathrm{eV}$ was made to determine experimental ionization energies (IEs) of these species (see Figure S6). The experimental IEs were then compared to literature values [18] or zero-pointenergy-corrected adiabatic ionization energies calculated from the composite CBS-QB3 method [19] using Gaussian [20] with an estimated accuracy around $0.1 \mathrm{eV}$.

For each species, the calculation has been performed for the conformer of lowest energy. For $m / z$ 48, as shown in Figure S6, the signal starts to increase for an energy around $9.9 \mathrm{eV}$, which is in agreement with the calculated IE $(9.84 \mathrm{eV})$ for $\mathrm{CH}_{3} \mathrm{OOH}$. Figure 1 also shows the presence of a compound at $m / z 62$ during SPI-MS experiments. A compound at this $m / z$ was also detected with the SVUV-PIMS during $n$-butane oxidation and was tentatively identified from its calculated IE $(9.61 \mathrm{eV})$ as ethylhydroperoxide [10].

For $m / z 100,104$, and 118 , literature or calculated IEs of the most expected isomers are displayed in Table 1.

For $m / z$ 100, the most probable structures would be 2,4-pentanedione and 3,5-pentanedione. For $m / z$ 104, the main observed isomer was 2-hydroperoxy-pentane with an IE of $9.35 \mathrm{eV}$, in good agreement with the experimental value. For $m / z$ 118, while the formation of 4hydroperoxy-2-pentanone would be kinetically favored, the main observed isomers seem to be 1-hydroperoxy-3-pentanone and 3-hydroperoxy-pentanal, with an experimental IE close to 9.3 $\mathrm{eV}$.

Note that the formation of 2,4-pentanedione and 3,5-pentanedione was also observed by gas chromatography [9]. However, the GC-derived shapes of temperature evolution are very different from those obtained using mass spectrometry, which display a sharp peak around 600 $\mathrm{K}$. This result indicates a possible contribution from the decomposition of fragile ketohydroperoxides in the GC transfer line, as previously discussed [3]. 
Table 1: IE (eV) of the most expected isomers of $m / z 100,104$, and 118 deriving from $n$-pentane.

\begin{tabular}{|c|c|c|c|}
\hline Mass & Name & Structure & IE $(\mathrm{eV})$ \\
\hline \multirow{2}{*}{100} & 2,4-pentandione & & $8.85^{*} 8.95^{* *}$ \\
\hline & 3,5-pentandione & & $9.26^{* *}$ \\
\hline \multirow{3}{*}{104} & 1-hydroperoxy-pentane & $9^{3} 9^{3} g^{0}$ & $9.5^{*} 9.42^{* *}$ \\
\hline & 2-hydroperoxy-pentane & & $9.35^{*} 9.26^{* *}$ \\
\hline & 3-hydroperoxy-pentane & & $9.17^{* *}$ \\
\hline \multirow{3}{*}{118} & 4-hydroperoxy-2-pentanone & & $9.04^{* *}$ \\
\hline & 1-hydroperoxy-3-pentanone & & $9.26^{* *}$ \\
\hline & 3-hydroperoxy-pentanal & & $9.30^{* *}$ \\
\hline
\end{tabular}

${ }^{*}$ From [18]; ${ }^{* *}$ Theoretical calculations.

While the ionization cross sections of hydroperoxides and diones are not directly available, we have estimated them from a group-additivity method (see SM). Figure 3 presents the experimental temperature evolution of mole fractions of the three types of hydroperoxides with a saturated alkyl chain, measured with the two types of mass spectrometers for the stoichiometric mixture. The shapes of the profiles obtained with both experimental devices are similar, displaying sharp peaks and maximum formation occurring close to $600 \mathrm{~K}$. The agreement between both methods looks satisfactory enough given the differences in the sampling methods (capillary and molecular beam) and that measurements were made for a significantly lower number of temperatures using SVUV-PIMS compared to SPI-MS.

As in our previous studies [3], large amounts of diones are observed. This can be seen in the present study with both spectrometers. Here also, the shapes of the profiles obtained with both techniques are similar with large peaks and maximum formation at a temperature $20 \mathrm{~K}$ higher than for hydroperoxides. While the two sampling methods are very different, the deviation in the maximum mole fractions of peroxides and diones shown in Figure 3 is about a factor of 2. 


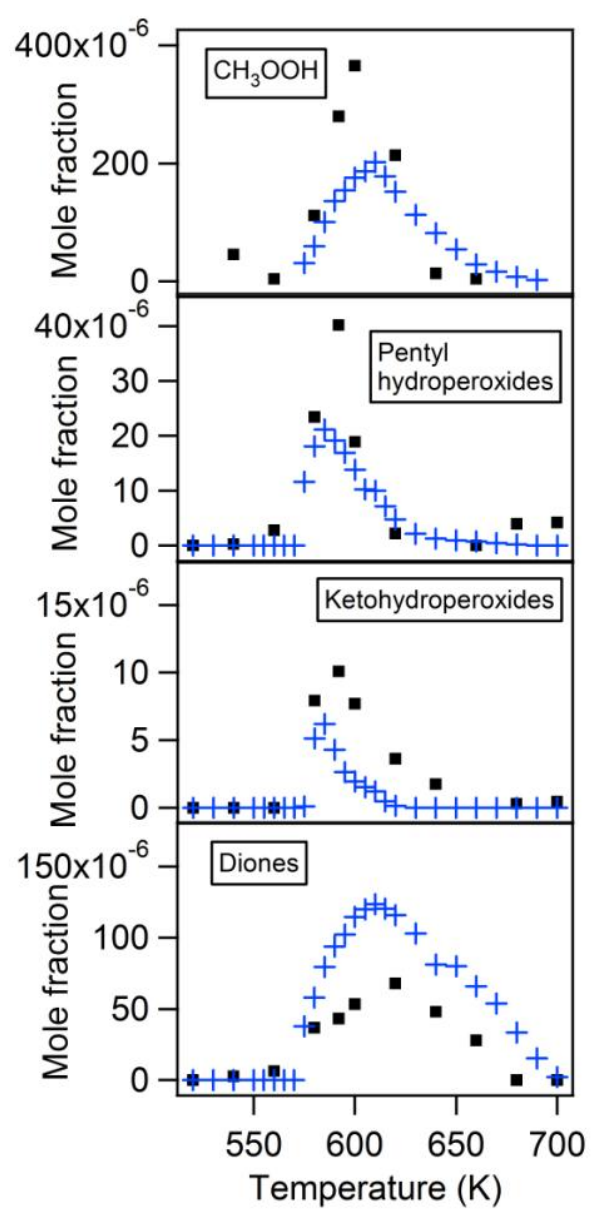

Figure 3: Experimental temperature evolution of the mole fractions of peroxides and diones for stoichiometric mixtures measured with SVUV-PIMS (squares) and SPI-MS (crosses).

Figure 4 displays the experimental temperature evolution of the mole fractions of diones and of the four saturated hydroperoxides that were measured using SPI-MS for equivalence ratios 0.5 , 1 , and 2 .

It shows a significant enhancement of the maximum mole fraction of these five products when $\varphi$ decreases. While the peak of formation of $\mathrm{C}_{1}-\mathrm{C}_{2}$ alkylhydroperoxides occurs at the same temperature regardless of $\phi$, this maximum occurs about $10 \mathrm{~K}$ higher at $\varphi=2$ than at $\varphi=0.5$ for pentylhydroperoxides, ketohydroperoxides, and diones. This comparison indicates that $\mathrm{C}_{1}-\mathrm{C}_{2}$ alkylhydroperoxide chemistry is only related to that of small intermediates, while the formation of $\mathrm{C}_{5}$ products is closely linked to the fuel reactions.

The temperature-profile shapes for the alkylhydroperoxides in Figure 4 are predicted well by the model of [9], as is the evolution of these profiles with equivalence ratio. The computed molefraction values are in very good agreement with the experimental data for $C_{1}, C_{2}$, and $C_{5}$ hydroperoxides considering the estimation of cross-sections. Rate analyses show that at $600 \mathrm{~K}$ these alkylhydroperoxides are mainly produced from reactions involving the disproportionation of $\mathrm{HO}_{2}$ and alkylperoxy radicals.

Ketohydroperoxide mole fractions are overestimated by a factor of about 125 , which could be due to weaknesses in the model but also to decomposition of these fragile species during their 
sampling and analyses, even if the good agreement shown in Figure 3 between the two experimental mass-spectrometry sets of experimental data does not support this last remark. Note also that the predicted maximum formation occurs at a temperature about $10 \mathrm{~K}$ lower than in experiments.

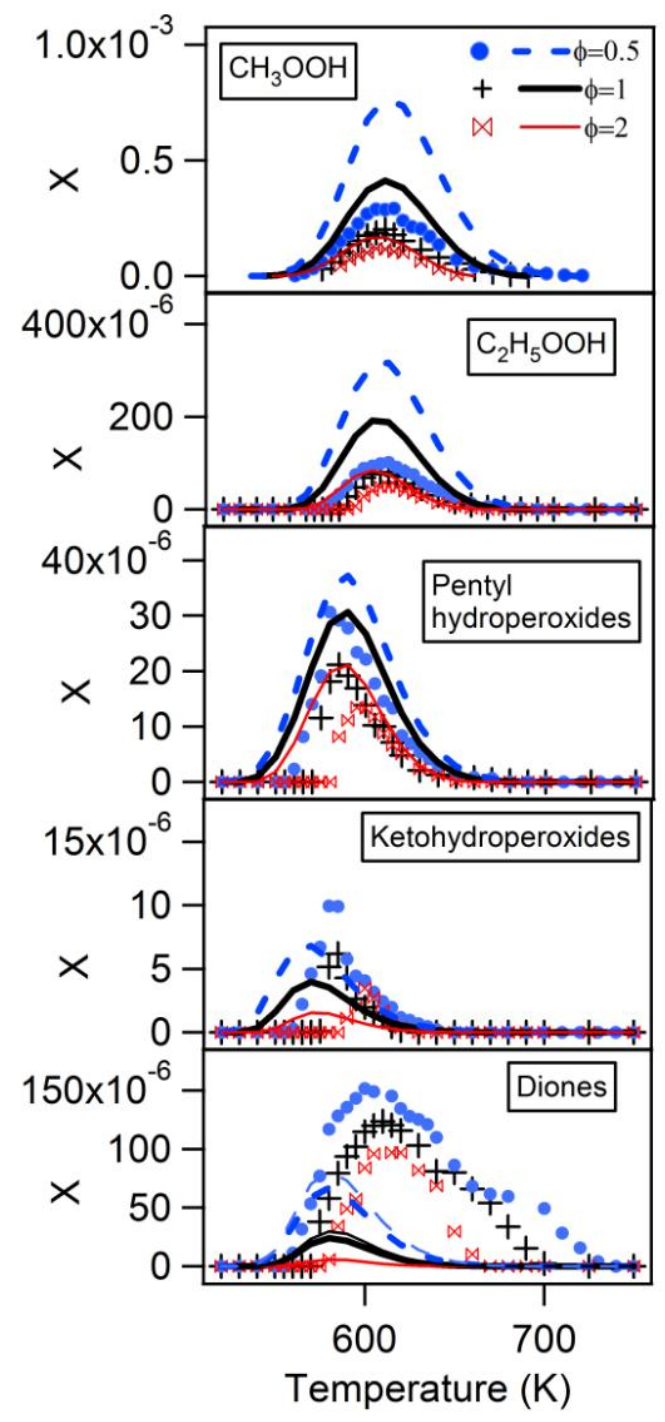

Figure 4: Temperature evolution of the mole fraction $\mathrm{X}$ of hydroperoxides and diones at various equivalence ratios. Experimental (SPI-MS, symbols) and computed (lines with ketohydroperoxide values divided by 125) using model of [9] for hydroperoxides and with changes adapted from [14] for diones.

For the formation of diones, reactions involving H-abstraction from the ketohydroperoxides and a rapid decomposition of the obtained radicals have been proposed [14]. In the Galway model [9], only $\mathrm{H}$-abstractions of ketohydroperoxides by $\mathrm{OH}$ radicals were considered. In the model updated in this, $\mathrm{H}$-abstractions of ketohydroperoxides by other radicals were also included (see SM). However, both models simulated the formation of these compounds satisfactorily. Slightly more dione formation can be observed with the updated model due to some influence of $\mathrm{H}$ - 
abstractions by $\mathrm{H}$-atoms and $\mathrm{CH}_{3} \mathrm{O}$ radicals. In addition, both models fail in reproducing the dione maximum-formation position by about $30 \mathrm{~K}$, indicating that the proposed mechanism does not fully explain the formation of these oxygenated products.

\subsection{Alkenylhydroperoxide identification and quantification}

Mass spectra from both SVUV-PIMS and SPI-MS show peaks at $m / z 74$ that could correspond to propanoic acid, as already described during the oxidation of several $C_{3}-C_{7}$ alkanes [3]. Acetic acid has been detected by SVUV-PIMS but not using SPI-MS at $10.6 \mathrm{eV}$ because its IE is $10.69 \mathrm{eV}$ [18]. In Figure 1 and the SVUV data, two other peaks at $m / z \quad 88$ and 102 could be attributed to butanoic and pentanoic acids; however, these $m / z$ signals could also be alkenylhydroperoxides obtained by combination of $\mathrm{HO}_{2}$ radicals and resonance-stabilized radicals deriving from propene, butenes, and pentenes, respectively.

To confirm the identification of these species, an experimental SVUV-PIMS sweep of photon energies has been made to determine experimental ionization energies (see Figure 5). Experimental IEs were then compared to literature [18] or calculated values. The IEs corresponding to the most expected isomers are displayed in Table 2.

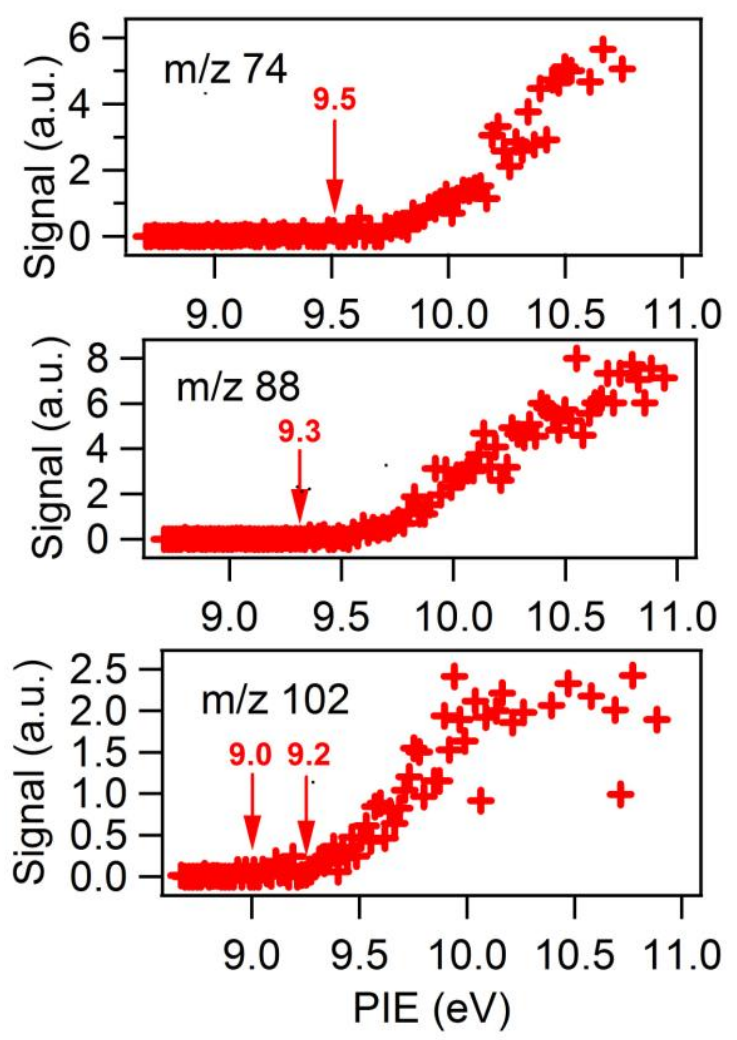

Figure 5: Photoionization efficiency (PIE) spectra of $m / z$ 74, 88, and 102 during stoichiometric $n$-pentane oxidation at $630 \mathrm{~K}$.

Figure 5 suggests that experimental IEs correspond mainly to IEs of alkenylhydroperoxides, in agreement with the fact that propanoic acid has not been detected during gas-chromatographic analyses [9]. For the $C_{5}$ alkenylhydroperoxides, Figure 5 shows that there is a small rise of the signal from $9 \mathrm{eV}$ and then a larger one from $9.2 \mathrm{eV}$, indicating the possible presence of the three 
isomers shown in Table 2. The compounds at $\mathrm{m} / z 102$ could also correspond to $\mathrm{C}_{5}$ species including a ketone and an alcohol functions which can be obtained via reactions of ketohydroperoxides as previously proposed for $n$-butane [10]. However the calculated IEs for the most expected isomers of such species were found to stand below $8.9 \mathrm{eV}$ or above $9.3 \mathrm{eV}$.

Table 2: Ionization energies of the most expected isomers of $m / z=74,88$, and 102.

\begin{tabular}{|c|c|c|c|}
\hline Mass & Name & Structure & $\mathrm{IE}(\mathrm{eV})$ \\
\hline \multirow{2}{*}{74} & Propanoic acid & & $10.44^{*}$ \\
\hline & Allylhydroperoxide & & $9.55^{* *}$ \\
\hline \multirow{3}{*}{88} & Butanoic acid & & $10.30^{*} 10.27^{* *}$ \\
\hline & But-1-enyl 3-hydroperoxide & & $9.29^{* *}$ \\
\hline & But-2-enyl 1-hydroperoxide & & $9.32^{* *}$ \\
\hline \multirow{4}{*}{102} & Pentanoic acid & & $10.08^{* *}$ \\
\hline & Pent-1-enyl 3-hydroperoxide & & $9.18^{* *}$ \\
\hline & Pent-2-enyl 1-hydroperoxide & & $9.25^{* *}$ \\
\hline & Pent-2-enyl 4-hydroperoxide & & $8.99^{* *}$ \\
\hline
\end{tabular}

${ }^{*}$ From $[18] ;{ }^{* *}$ Theoretical calculations.

Figure 6 displays the SPI-MS experimental evolution with temperature of the mole fractions of the compounds that were identified as alkenylhydroperoxides at $\varphi=0.5,1$, and 2 . Figure 6 also shows that, while the signal-to-noise ratio of the SPI-MS experiments was better than the SVUVPIMS experiments, SVUV-PIMS mole fractions profiles were also obtained in the case of butenyl and pentenylhydroperoxides, with a very good agreement between the two sources of data.

The formation of these three alkenylhydroperoxides, which are produced in similar amounts, is favored for lean mixtures, but the equivalence ratio has less influence for hydroperoxides with an unsaturated chain than for those with an alkyl chain, indicating that their origin is not only via oxygen-addition pathways, but also through combinations of alkenyl radicals with $\mathrm{HO}_{2}$ radicals.

To simulate the $\mathrm{C}_{4}$ and $\mathrm{C}_{5}$ alkenylhydroperoxide formation, the Galway [9] model was used, adding combinations of butenyl and pentenyl radicals with $\mathrm{HO}_{2}$ radicals with the kinetics proposed by [9] for allyl radicals (detailed in SM). Considering the uncertainties due to estimated cross-sections, the deviation in the predicted formation of the $\mathrm{C}_{3}$ and $\mathrm{C}_{5}$ alkenylhydroperoxides is not alarming, even if it is surprising that a large deviation is obtained for allylhydroperoxide that has the best-known chemistry among these three species. For yet unknown reasons, the main failure in the simulations is that the temperature of the maximum of formation is significantly displaced (about $30 \mathrm{~K}$ ) toward lower temperatures and that the 
shoulder observed at the highest temperature for lean mixtures is not reproduced. At $600 \mathrm{~K}$, rate analyses indicate that allylhydroperoxide is formed mainly by combination of allyl and $\mathrm{HO}_{2}$ radicals. The combination of alkenyl and $\mathrm{HO}_{2}$ radicals is also important to explain the formation of the $\mathrm{C}_{5}$ alkenylhydroperoxides, but a significant contribution is also observed for $\mathrm{HO}_{2}$ eliminations from peroxyhydroperoxyalkyl radicals, originally present in the model of [9]. When adding alkenyl $+\mathrm{HO}_{2}$ combination reactions, maximum formation is displaced by $10 \mathrm{~K}$ higher compared to simulations with the model of [9]. For $\mathrm{C}_{5}$ alkenylhydroperoxides, simulations at the peak of formation indicate the following isomer distribution: $48.1 \%$ pent-2-enyl-1hydroperoxide (51\% yielded from $\mathrm{HO} 2$ eliminations), 39.4\% pent-2-enyl-4-hydroperoxide (30\% from $\mathrm{HO}_{2}$ eliminations), and $12.5 \%$ pent-1-enyl-3-hydroperoxide (28\% from $\mathrm{HO}_{2}$ eliminations). Despite SPI-MS and SVUV-PIMS measurements being in good agreement, a large deviation was obtained when modeling butenylhydroperoxide profiles. This difference probably indicates problems in modeling the low-temperature chemistry of butenes.

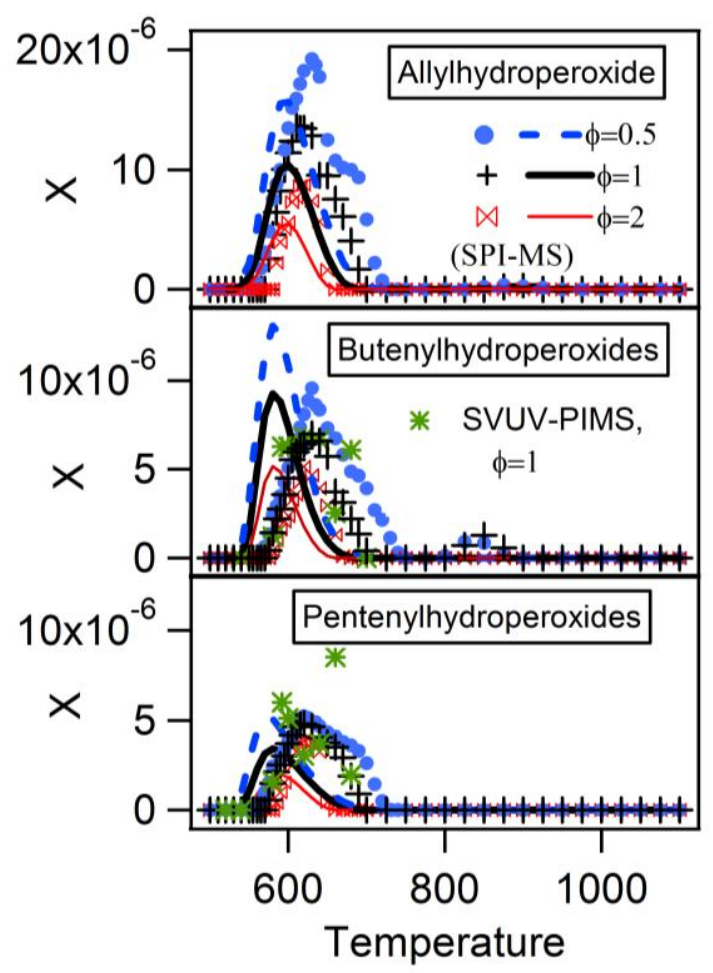

Figure 6: Experimental and computed temperature evolutions of the mole fractions $(\mathrm{X})$ of $\mathrm{C}_{3}-\mathrm{C}_{5}$ alkenylhydroperoxides: measurements by SPI-MS at various equivalence ratios, measurements by SVUV-PIMS for stoichiometric mixtures, and simulations with modified model (details in SM); model values multiplied by 10,100 and 3 for allylhydroperoxide, butenylhydroperoxides, and pentenylhydroperoxides, respectively.

\section{5. $\mathrm{H}_{2} \mathrm{O}_{2}$ quantification}

Figure 7 presents the temperature evolution of $\mathrm{H}_{2} \mathrm{O}_{2}$ mole fractions for $\varphi=0.5,1$, and 2 . For stoichiometric mixtures, both cw-CRDS and SVUV-PIMS measurements are displayed with an excellent agreement between both techniques. These profiles clearly show two zones with distinct maxima, one below $800 \mathrm{~K}$ and one above. Figure 5 shows a very large effect of equivalence ratios on the value of the maxima in both zones. 


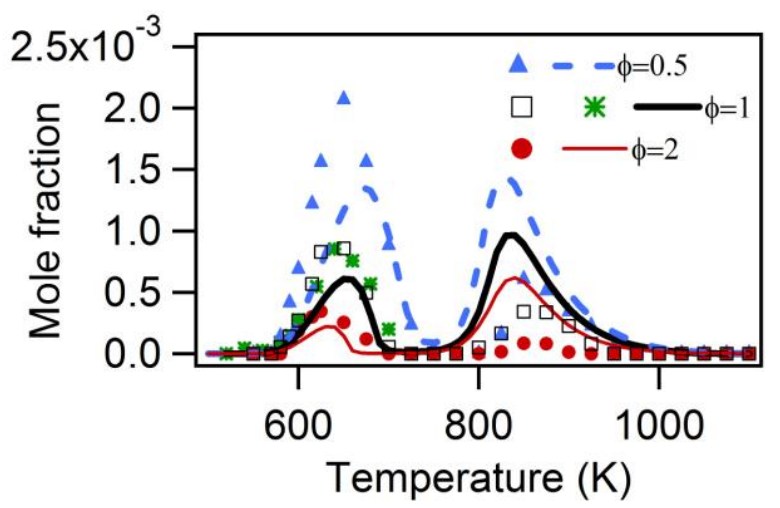

Figure 7: Temperature evolution of the mole fraction of hydrogen peroxide; experimental cW-CRDS (triangles, squares and circles) and SVUV-PIMS (stars) versus simulated (lines, with the model of [9]).

Simulations with the unchanged model lead to satisfactory agreement with experimental data below $800 \mathrm{~K}$ but to overprediction above this temperature, which could be due to wall quenching, as discussed in [12].

Figure 8 presents experimental temperature evolution of mole fractions of the eight peroxides quantified in this work. $\mathrm{H}_{2} \mathrm{O}_{2}$ and methylhydroperoxide are by far the most abundant. Clear differences in the temperatures for peak mole fraction are observed: saturated $\mathrm{C}_{5}$ hydroperoxides have peaks at the lowest temperature, followed by $\mathrm{C}_{1}-\mathrm{C}_{2}$ alkylhydroperoxides, then the alkenylhydroperoxides, and finally $\mathrm{H}_{2} \mathrm{O}_{2}$ not far after.

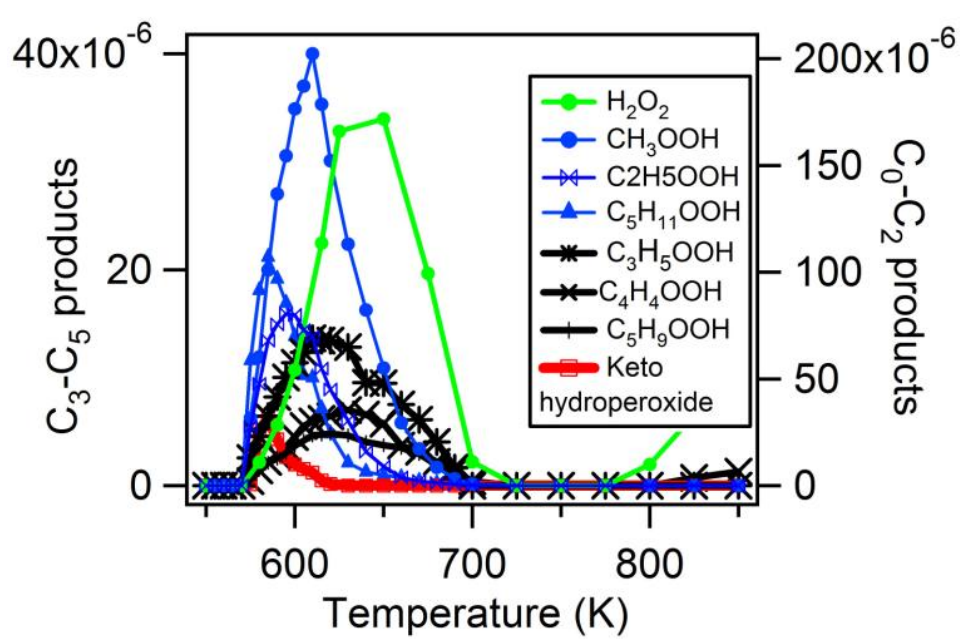

Figure 8: Experimental temperature evolution of the mole fraction of all the hydroperoxides obtained during stoichiometric $n$-pentane oxidation.

\section{Conclusion}

Oxidation of $n$-pentane has been studied in a JSR, using a combination of three advanced techniques: SVUV-PIMS, SPI-MS, and cw-CRDS. Species evolution has been followed for ketene, diones, and eight hydroperoxides including $C_{1}, C_{2}, C_{5}$ alkylhydroperoxides, $C_{5}$ 
ketohydroperoxides, $\mathrm{C}_{3}, \mathrm{C}_{4}, \mathrm{C}_{5}$ alkenylhydroperoxides, and $\mathrm{H}_{2} \mathrm{O}_{2}$. A model recently developed at Galway predicts the formation of $\mathrm{H}_{2} \mathrm{O}_{2}$, ketene, methylhydroperoxide, ethylhydroperoxide, and pentylhydroperoxides well, but it shows considerable deviations when simulating unsaturated hydroperoxides. This finding indicates a need for better understanding of the chemistry of these last hydroperoxides.

\section{Acknowledgment}

This work was supported by European Commission ("Clean ICE" ERC Advanced Research Grant) and by COST Actions CM0901 and 1404. The authors thank John Bugler and Henry Curran for providing their mechanism before the submission of the related paper [8].

\section{Supplementary Materials}

- Supplementary description

- Experimental data of the oxidation of $n$-pentane in a JSR

\section{References}

[1] S. Saxena, I.D. Bedoya, Prog. Energy Combust. Sci., 39 (2013), 457-488

[2] J. Zádor, C.A. Taatjes, R.X. Fernandes, Prog. Energy Combust. Sci., 37 (2011), 371-421

[3] 0. Herbinet, F. Battin-Leclerc, Int. J. Chem. Kinet., 46 (2014), 619-639

[4] K. Moshammer, A.W. Jasper, D.M. Popolan-Vaida, A. Lucassen, P. Diévart, H. Selim, A.J. Eskola, C.A. Taatjes, S.R. Leone, S.M. Sarathy, Y. Ju, P. Dagaut, K. Kohse-Höinghaus, N. Hansen, J. Phys. Chem. A, 119 (2015), 7361-7374

[5] C.K. Westbrook, W.J. Pitz, M. Mehl, P.-A. Glaude, O. Herbinet, S. Bax, F. Battin-Leclerc, O. Mathieu, E.L. Petersen, J. Bugler, H.J. Curran, J. Phys. Chem. A, 119 (2015), 7462-7480

[6] N.L. Le Tan, M. Djehiche, C.D. Jain, P. Dagaut, G. Dayma, Fuel, 158 (2015), 248-252

[7] A. Rodriguez, O. Frottier, O. Herbinet, R. Fournet, R. Bounaceur, C. Fittschen, F. Battin-Leclerc, J. Phys. Chem. A, 119 (2015), 7905-7923

[8] J. Bugler, K.P. Somers, E.J. Silke, H.J. Curran, J. Phys. Chem. A, 119 (2015), 7510-7527

[9] J. Bugler, A. Rodriguez, O. Herbinet, F. Battin-Leclerc, C. Togbé, G. Dayma, P. Dagaut, H. Curran, Proc. Combust. Inst. (2017), 36, 441-448

[10] F. Battin-Leclerc, O. Herbinet, P.-A. Glaude, R. Fournet, Z. Zhou, L. Deng, H. Guo, M. Xie, F. Qi, Proc. Combust. Inst., 33 (2011), 325-331 
[11] O. Herbinet, F. Battin-Leclerc, S. Bax, H.L. Gall, P.-A. Glaude, R. Fournet, Z. Zhou, L. Deng, H. Guo, M. Xie, F. Qi, Phys. Chem. Chem. Phys., 13 (2011), 296-308

[12] C. Bahrini, P. Morajkar, C. Schoemaecker, O. Frottier, O. Herbinet, P.-A. Glaude, F. BattinLeclerc, C. Fittschen, Phys. Chem. Chem. Phys., 15 (2013), 19686-19698

[13] A.E. Parker, C. Jain, C. Schoemaecker, P. Szriftgiser, O. Votava, C. Fittschen, Appl. Phys. B, 103 (2010), 725-733

[14] M. Pelucchi, M. Bissoli, C. Cavallotti, A. Cuoci, M. Pelucchi, A. Frassoldati, E. Ranzi, A. Stagni, Energy Fuels, 28 (2014), 7178-7193

[15] A. Cuoci, A. Frassoldati, T. Faravelli, E. Ranzi, Comp. Phys. Com., 192 (2015), 237-264

[16] C.S. McEnally, L.D. Pfefferle, Combust. Flame, 121 (2000), 575-592

[17] B. Yang, J. Wang, T.A. Cool, N. Hansen, S. Skeen, D.L. Osborn, Int. J. Mass Spectrsc., 309 (2012), 118-128

[18] NIST Chemistry Webbook; NIST Standard Reference Database 69; NIST, Gaithersburg, MD, 2005: http://webbook.nist.gov/chemistry

[19] J.A. Montgomery, M.J. Frisch, J.W. Ochterski, G.A. Petersson, J. Chem. Phys., 110 (1999), $2822-2827$

[20] M.J. Frisch et al. Gaussian03, revision B05; Gaussian, Inc.: Wallingford, CT, 2004. 